\title{
Enhanced Permeability of Fe-Based Amorphous Powder Cores Realized through Selective Incorporation of Carbonyl Iron Powders at Inter-Particle Voids
}

\author{
Hea-Ran Kim ${ }^{1,2}$, Min-Sun Jang ${ }^{1}$, Yeong-Gyun Nam ${ }^{1,3}$, Yun-Seok Kim ${ }^{2}$, Sang-Sun Yang ${ }^{1}$, Yong-Jin Kim ${ }^{1}$ \\ and Jae-Won Jeong $1, * \mathbb{D}$ \\ 1 Metal Powder Department, Korea Institute of Materials Science (KIMS), Changwon 51508, Korea; \\ hearan@kims.re.kr (H.-R.K.); msjang@kims.re.kr (M.-S.J.); namceo@kims.re.kr (Y.-G.N.); \\ nanoyang@kims.re.kr (S.-S.Y.); yjkim@kims.re.kr (Y.-J.K.) \\ 2 Department of Materials Science and Engineering, Sungkyunkwan University (SKKU), Suwon 16419, Korea; \\ yunseokkim@skku.edu \\ 3 School of Materials Science and Engineering, Pusan National University, Busan 46241, Korea \\ * Correspondence: jeongjw1204@kims.re.kr
}

check for

updates

Citation: Kim, H.-R.; Jang, M.-S.; Nam, Y.-G.; Kim, Y.-S.; Yang, S.-S.; Kim, Y.-J.; Jeong, J.-W. Enhanced Permeability of Fe-Based Amorphous Powder Cores Realized through Selective Incorporation of Carbonyl Iron Powders at Inter-Particle Voids. Metals 2021, 11, 1220. https:// doi.org/10.3390/met11081220

Academic Editor: Ariosto Medina

Received: 28 June 2021

Accepted: 26 July 2021

Published: 30 July 2021

Publisher's Note: MDPI stays neutral with regard to jurisdictional claims in published maps and institutional affiliations.

Copyright: (c) 2021 by the authors. Licensee MDPI, Basel, Switzerland. This article is an open access article distributed under the terms and conditions of the Creative Commons Attribution (CC BY) license (https:// creativecommons.org/licenses/by/ $4.0 /)$.

\begin{abstract}
In this study, we demonstrate a hybrid multimodal soft magnetic composite (SMC) comprising gas-atomized spherical amorphous powder (AP) and carbonyl-iron powder (CIP), and present its enhanced electromagnetic properties. CIP is selectively incorporated into voids between AP, and deforms during compression, effectively reducing the pores, resulting in high packing density of the core, where CIP magnetically bridges AP and helps magnetic domain rotation much efficiently. The hybrid SMC with the addition of $20 \mathrm{wt}$. $\%$ CIP showed constant effective permeability of 57 up to $1 \mathrm{MHz}$, a remarkable 63\% increase compared with the AP core, while DC bias superimposing retention level of $61 \%$ was secured with the help of high magnetization of CIP. In addition, the effect of $\mathrm{SiO} 2$ surface insulation, prepared by the sol-gel process, on the high-frequency magnetic properties of hybrid SMCs, was also evaluated. It is thus revealed that the high-frequency dynamic loss of the hybrid core, originating from intra-particle eddy current loss and anomalous loss component, and inter-particle eddy currents are negligibly small. We believe that our approach using AP/CIP multimodal hybrid SMCs is an effective way of achieving high permeability as well as high DC bias characteristics at high frequencies. This process will be highly beneficial for the miniaturization of power inductors.
\end{abstract}

Keywords: soft magnetic composite; amorphous powder; carbonyl iron powder; surface insulation; multimodal core

\section{Introduction}

As mobile devices such as smartphones and tablet PCs become widely distributed and thinner and lighter, miniaturization of the electronic components inside the devices is urgently required [1]. Power inductors, essential components for power management of electronic devices, also must be miniaturized; they must operate at high frequencies and inevitably be capable of dealing with high currents. Following this trend, it is necessary to supply magnetic powder cores with high permeability, low core loss, and good DC bias characteristics, especially at high frequencies.

Fe-based soft magnetic amorphous powders (APs) are considered ideal materials for magnetic powder cores due to their excellent magnetic properties such as low coercivity, high resistance, and good DC bias characteristics [2,3]. Due to the disordered configuration of atoms in amorphous alloys, these materials have zero magnetocrystalline anisotropy, which ensures high permeability and low coercivity [4,5]. In addition, due to their high resistivity, Fe-based amorphous alloys exhibit extremely low eddy current loss at high 
frequencies, making them suitable as high frequency soft magnetic composite (SMC) materials [6,7].

Soft magnetic amorphous powders prepared by gas or water atomization have spherical shapes with average particle sizes of 15 100 $\mu \mathrm{m}$ [8], ensuring isotropic magnetic properties and high packing density; these materials are particularly suitable for powder cores, especially for work at frequencies over $200 \mathrm{kHz}$. With evenly distributed micro-gaps between particles, amorphous powder SMCs provide modulated permeability as well as minimized magnetic field leakage around the core.

However, due to their extremely hard and brittle nature, amorphous powders have poor moldability at temperatures below the glass transition, resulting in low compression density and low mechanical strength $[9,10]$. In addition, Fe content in amorphous soft magnetic alloys is generally limited to below $80 \%$ due to the incorporation of a great quantity of glass-forming metalloid elements [11]; also, the saturation magnetization $\left(M_{\mathrm{S}}\right)$ of amorphous alloys is restricted to less than $1.6 \mathrm{~T}$ [12], which is very low compared with those of conventional crystalline pure iron (2.15 T) [13] or Fe-Si alloys (1.8 2.0 T) [14].

The most significant limitation of SMCs comprising low- $M_{\mathrm{s}}$ amorphous powders is poor DC bias. Enhancing the $M_{\mathrm{S}}$ of amorphous powder by carefully managing alloy composition is the best way to enhance permeability retention even with a high bias field; however, increasing Fe content in the alloy significantly deteriorates the glass-forming ability of the alloy [11], and obtaining spherical amorphous powders through gas or water atomization becomes extremely difficult due to the limited cooling rate $\left(10^{2} \sim 10^{4} \mathrm{~K} / \mathrm{s}\right)$ of the process [15].

Researchers have attempted to enhance DC bias characteristics by adding small crystalline particles in SMCs [16-18]. Composite cores mixed with amorphous powder and other magnetic crystalline powder can greatly improve the compaction density and magnetic performance, and reduce product cost. C. Chang et al. reported $10 \%$ addition of small FeSi powders into FeSiBPNb amorphous powder cores increased permeability while maintaining good DC bias characteristics [18]. C. Xia et al. also reported the improved density and magnetic properties of $\mathrm{FeSiCr}$ amorphous cores with the addition of carbonyliron powders (CIPs) [19].

For bimodal cores, it is known that packing density can be maximized when the particle size ratio between primary and secondary particles reaches 7:1 [20]. For example, to achieve high core density, if the size of the primary amorphous powders is several tens of microns, the size of secondary powders should be in the range of tens of microns.

Due to its genuine small size (several microns), CIP is considered a suitable candidate constituent that is perfectly suited for secondary constituents for bimodal SMCs. In addition, CIPs are comprised of pure iron and are highly ductile, so they are easily moldable and expected to effectively fill the voids between APs [21]. Low material cost for CIPs also supports commercial applications of AP/CIP hybrid SMCs.

In this study, we demonstrate a hybrid multimodal SMC comprising gas-atomized spherical amorphous powder and carbonyl-iron powder (AP/CIP hybrid SMCs), and present enhanced electromagnetic properties of this material, including significantly enhanced effective permeability and DC bias characteristics, compared with AP cores without CIP addition.

In addition, the effect of $\mathrm{SiO}_{2}$ surface insulation prepared by the sol-gel process on the high-frequency magnetic properties of hybrid SMCs was also evaluated. Recently, it has also been reported that inorganic insulation coatings such as $\mathrm{TiO}_{2}, \mathrm{SiO}_{2}$, soft ferrites and phosphates on the surface of soft magnetic powders were effective in the reduction of inter-particle eddy current loss [22-25]. The effect of surface insulation on the core density and permeability, and the high-frequency core-loss in terms of inter-particle eddy current loss, were systematically investigated. 


\section{Experimental Sections}

\subsection{Materials}

APs with the composition of $\mathrm{Fe}_{73} \mathrm{Si}_{6} \mathrm{~B}_{10} \mathrm{P}_{5} \mathrm{C}_{3} \mathrm{Mo}_{3}$ (at\%) were prepared through inert gas atomization (IGA). Then, $5 \mathrm{~kg}$ master alloys with a nominal composition of $\mathrm{Fe}_{73} \mathrm{Si}_{6} \mathrm{~B}_{10} \mathrm{P}_{5} \mathrm{C}_{3} \mathrm{Mo}_{3}$ (at \%) were prepared through induction melting using raw materials of $\mathrm{Fe}(99.9 \%), \mathrm{Si}(99.9 \%), \mathrm{FeB}(99.9 \%), \mathrm{Fe}_{3} \mathrm{P}(99.9 \%), \mathrm{FeC}(99.9 \%)$, and $\mathrm{FeMo}(99.9 \%)$. Further, gas atomization (with close-coupled nozzle) was performed with Ar gas ejection with the pressure of 80 bar to obtain amorphous soft magnetic powders. The obtained APs were then sieved under $45 \mu \mathrm{m}$, which resulted in mean particle size $\left(D_{50}\right)$ of $25.05 \mu \mathrm{m}$.

CIPs $\left(\mathrm{D}_{50}=3.74 \mu \mathrm{m}\right)$ were supplied by BASF Co. (Ludwigshafen, Germany) Tetraethyl orthosilicate (TEOS, 95\% purity), ammonia solution $\left(\mathrm{NH}_{4} \mathrm{OH}, 28 \sim 30 \%\right.$ purity), and ethanol $\left(\mathrm{C}_{2} \mathrm{H}_{5} \mathrm{OH}, 99.9 \%\right.$ purity) were purchased from Samchun Pure Chemical Co. (Pyeongtaek, Korea) and used as received. Deionized (DI) water was prepared by an automatic pure water distiller.

\subsection{Surface Insulation Coating of AP and CIP}

The surfaces of AP and CIP were coated with a $\mathrm{SiO}_{2}$ insulation layer by a sol-gel procedure. TEOS $(2 \mathrm{~mL})$ and ethanol $(40 \mathrm{~mL})$ were stirred at $300 \mathrm{rpm}$ for $15 \mathrm{~min}$ at $60{ }^{\circ} \mathrm{C}$. Another mixture of ammonia $(28 \mathrm{~mL})$ and DI water $(170 \mathrm{~mL})$ was stirred for $15 \mathrm{~min}$ at $60{ }^{\circ} \mathrm{C}$ at $500 \mathrm{rpm}$. Then, APs (100 g) or CIPs (100 g) were dispersed in mixed solutions of the above two solutions. The reaction proceeded for $10 \mathrm{~h}$ at $50{ }^{\circ} \mathrm{C}$ in an $\mathrm{N}_{2}$ atmosphere. The chemical reaction can be expressed by the following formulas [26]:

$$
\begin{gathered}
\mathrm{Si}\left(\mathrm{C}_{2} \mathrm{H}_{5} \mathrm{O}\right)_{4}+4 \mathrm{H}_{2} \mathrm{O} \rightarrow \mathrm{Si}(\mathrm{OH})_{4}+\mathrm{C}_{2} \mathrm{H}_{5} \mathrm{OH} \\
\mathrm{Si}(\mathrm{OH})_{4} \rightarrow \mathrm{SiO}_{2}+\mathrm{H}_{2} \mathrm{O}
\end{gathered}
$$

Surface-insulated APs or CIPs were separated from the solution using a permanent magnet; the dried powders were annealed at $250{ }^{\circ} \mathrm{C}$ for $1 \mathrm{~h}$ in an argon atmosphere.

\subsection{Fabrication of the SMCS}

Hybrid SMCs were prepared by mixing raw APs and CIPs, followed by high-pressure compaction molding. Here, cores with CIP content of $x$ wt.\% are denoted as "Cx". Core samples with CIP contents of $0,5,10,15$, and 20 wt. \% were designated as C0, C5, C10, $\mathrm{C} 15$, and $\mathrm{C} 20$, respectively. The powder was mixed with binding materials ( $2.5 \mathrm{wt} . \%$ epoxy resin) and thereafter compacted into toroidal powder cores with an outer diameter of $25 \mathrm{~mm}$ and an inner diameter of $15 \mathrm{~mm}$ at a pressure of $500 \mathrm{MPa}$ at room temperature. SMCs were cured at $150^{\circ} \mathrm{C}$ for $1 \mathrm{~h}$ in a vacuum and annealed at $475^{\circ} \mathrm{C}$ for $1 \mathrm{~h}$ in an argon atmosphere. By using surface-insulated APs and CIPs, three different types of hybrid SMCs, $\mathrm{AP} @ \mathrm{SiO}_{2}+\mathrm{CIP}, \mathrm{AP}+\mathrm{CIP} @ \mathrm{SiO}_{2}$, and $\mathrm{AP} @ \mathrm{SiO}_{2}+\mathrm{CIP} @ \mathrm{SiO}_{2}$, were prepared.

\subsection{Characterization}

The crystalline structure of the powder was analyzed using an X-ray diffractometer (XRD, D/Max 2500, Rigaku, Tokyo, Japan) with $\mathrm{Cu} \mathrm{K \alpha}$ radiation. The static magnetic properties of the powders were measured by a vibrating sample magnetometer (VSM, EZ9, MicroSense, Tempe, AZ, USA). The morphology and composition of the powder were observed using a field-emission scanning electron microscope (FE-SEM, MIRA3 LM, TESCAN, Brno, Czech Republic) equipped with an energy-dispersive X-ray spectrometer EDS (TESCAN, Brno, Czech Republic). The particle sizes of the AP and CIP powders were analyzed using a LASER particle size analyzer (LS13 320, Beckman Coulter, Brea, CA, USA). The core density was measured with Archimedes' method. The core loss was measured using an AC B-H analyzer (SY-8219, IWATSU ELECTRIC, Tokyo, Japan) in the frequency range of $10 \mathrm{kHz}-1 \mathrm{MHz}$ with a maximum applied induction of $100 \mathrm{mT}$. The permeability in the frequency range of $10 \mathrm{kHz}-1 \mathrm{MHz}$, and DC-bias properties, were observed by LCR meter (3260B, WAYNE KERR Electronics, Bognor Regis, UK). The coercive field of the cores 
was measured by DC B-H analyzer (Pemagraph c-500, Magnet-Physik, Köln, Germany) with applied field of $-1 \pm 1 \mathrm{kA} / \mathrm{m}$.

\section{Results and Discussion}

Analyses of the properties of the original AP and CIP were performed prior to the SMC fabrication, as shown in Figure 1. Figure 1a shows XRD patterns of the gas atomized AP and CIP. The XRD pattern of AP consisted of a broad halo pattern in the vicinity of $2 \theta=45^{\circ}$, without any noticeable sharp crystalline peaks. This indicates that the gas atomized powder with a diameter under $45 \mu \mathrm{m}$ retains an amorphous structure. The XRD pattern of the CIP shows only the diffraction peak of $\alpha$-Fe (JCPDF \# 87-0721), indicating single-phase pure $\alpha$-iron. Figure $1 b$ shows VSM measurement results of gas-atomized AP and CIP. Due to the incorporation of large amounts of metalloid elements, the saturation magnetization of AP $(136 \mathrm{emu} / \mathrm{g})$ was much lower than that of the CIP powders $(215 \mathrm{emu} / \mathrm{g})$. Surface SEM images and particle size analysis results for the AP and CIP powders are shown in Figure $1 \mathrm{c}, \mathrm{d}$, respectively. Both AP and CIP are spherical; the average particle sizes $\left(\mathrm{D}_{50}\right)$ of AP and CIP were $25.05 \mu \mathrm{m}$ and $3.74 \mu \mathrm{m}$, respectively. The particle size ratio between AP and CIP was 6.70:1, which is close to the ideal ratio for a bimodal core with the highest density. It is expected that, when AP and CIP are mixed, the density of the core can be increased by the CIP particles, which will fill the large pores between AP particles.
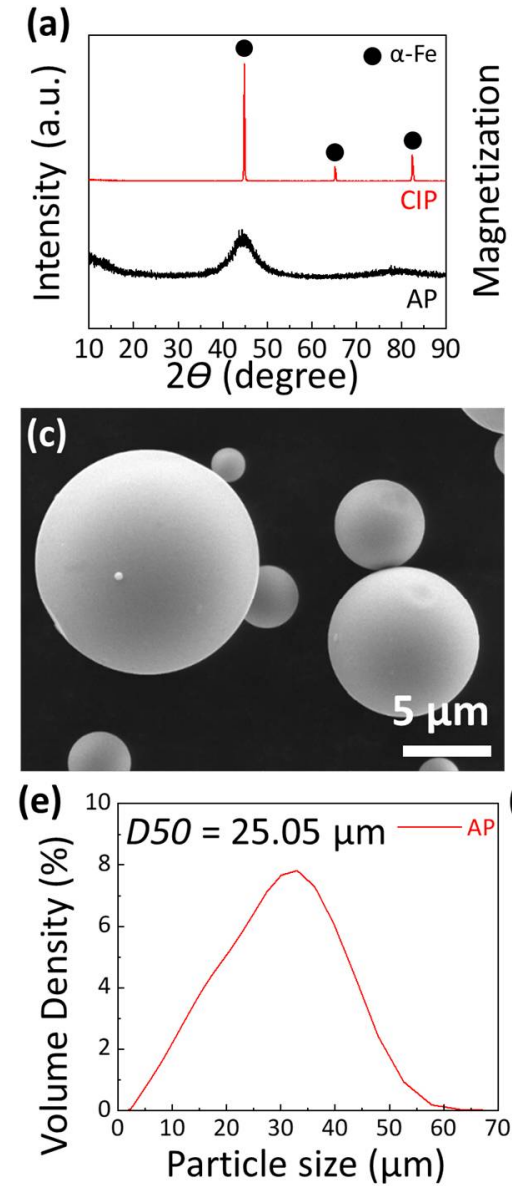
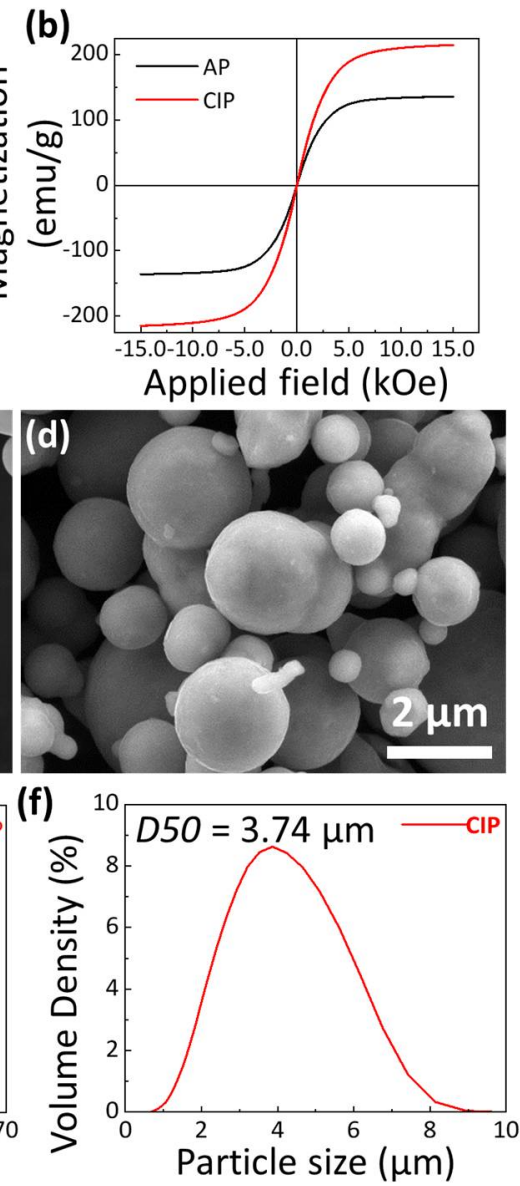

Figure 1. (a) XRD patterns of amorphous powder (AP) and carbonyl-iron powder (CIP). (b) Magnetic hysteresis loops of amorphous powder and carbonyl-iron powder. (c,d) SEM surface images of (c) amorphous powder and (d) carbonyl-iron powder. (e,f) Particle size distribution of (e) amorphous powder and (f) carbonyl-iron powder. The D50 is the volume median. 
Hybrid SMC was prepared by mixing AP and CIP at the predetermined weight ratio, followed by high-pressure compaction and heat treatment. Surface SEM images of the AP SMC (C0) and hybrid SMCs (C5-C20) are shown in Figure 2a-e. It can be seen that AP maintains its spherical shape even after the high pressure of core fabrication. As a result, large voids between large AP particles are inevitably generated in the core. Even though the AP has a size distribution of $2 \sim 45 \mu \mathrm{m}$, the number density of small AP particles is insufficient to fill the pores between large APs. In addition, intermediate-sized AP particles sizes in the range of 10 20 $\mu \mathrm{m}$ disturb the close packing of large-size AP particles, leading to enlarged interparticle spacing.
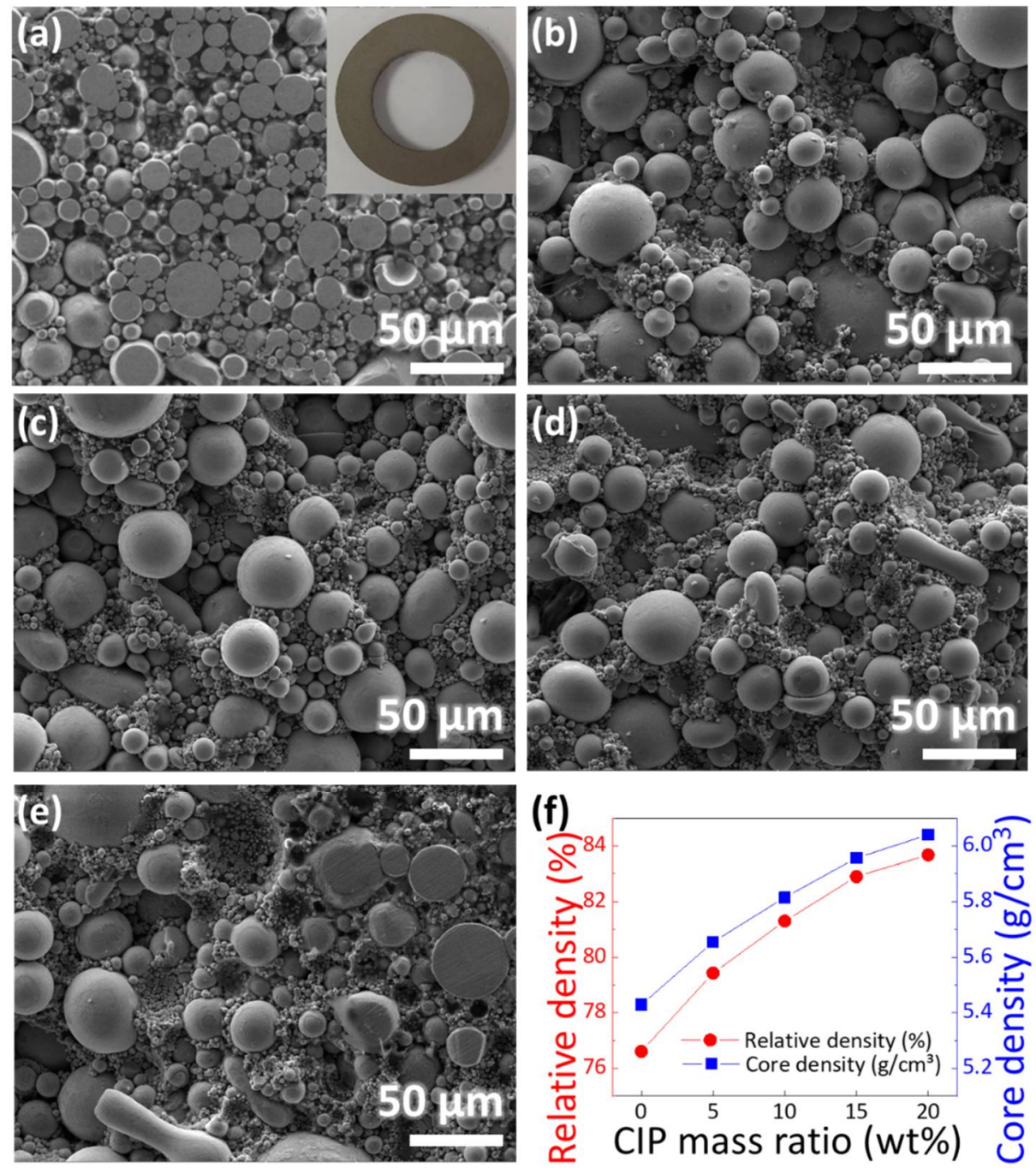

Figure 2. (a-e) SEM surface images of amorphous SMCs with (a) 0 wt.\%, (b) 5 wt.\%, (c) 10 wt.\%, (d) $15 \mathrm{wt} . \%$, and (e) $20 \mathrm{wt} . \%$ CIPs. Inset shows photograph of core sample. (f) Effects of CIP mass ratio on relative density and core density of amorphous SMCs with 0-20 wt.\% CIP addition.

On the other hand, hybrid SMCs with CIP addition show densely packed structures in which large pores are almost eliminated, as shown in the SEM images in Figure $2 b-e$. CIP particles with a mean particle size of $\sim 4 \mu \mathrm{m}$ are sufficiently small to be located at voids between AP particles; as a result, the voids are effectively filled. In addition, pure-iron CIP particles possess high ductility, and easily deform during the high-pressure compaction process. The packing density of SMCs was thus significantly enhanced.

Figure $2 \mathrm{f}$ shows the apparent density and corresponding relative density of the hybrid SMC depending on the CIP weight fraction in the core. As the CIP weight fraction 
increases, the core density increases, and C20 shows both the highest relative density and the highest apparent core density. This is attributable to the increased packing density of the hybrid core and also to the density of CIP $\left(7.8 \mathrm{~g} / \mathrm{cm}^{3}\right)$, which is higher than that of AP $\left(7.087 \mathrm{~g} / \mathrm{cm}^{3}\right)$. Interestingly, relative density also increases as the CIP weight fraction increases because the CIP particles are selectively incorporated in the voids between AP particles; the resulting particles deform during compaction, effectively reducing pores and resulting in increased packing density of cores. The powder density and apparent core density with corresponding relativity are also summarized in Table 1.

Table 1. Mixing ratio of amorphous and carbonyl-iron power for hybrid SMCs and corresponding density.

\begin{tabular}{|c|c|c|c|c|c|c|c|}
\hline \multirow{2}{*}{ Samples } & \multicolumn{2}{|c|}{ Weigh Ratio (\%) } & \multicolumn{2}{|c|}{ Volume Ratio (\%) } & \multirow{2}{*}{$\begin{array}{c}\text { Core } \\
\text { Density } \\
\left(\mathrm{g} / \mathrm{cm}^{3}\right)\end{array}$} & \multirow{2}{*}{$\begin{array}{c}\text { Powder } \\
\text { Density * } \\
\left(\mathrm{g} / \mathrm{cm}^{3}\right)\end{array}$} & \multirow{2}{*}{$\begin{array}{c}\text { Relative } \\
\text { Density } \\
(\%)\end{array}$} \\
\hline & $\mathbf{A P}$ & CIP & AP & CIP & & & \\
\hline $\mathrm{CO}$ & 100 & 0 & 100 & 0 & 5.429 & 7.087 & 76.61 \\
\hline $\mathrm{C} 5$ & 95 & 5 & 95.44 & 4.56 & 5.655 & 7.120 & 79.43 \\
\hline $\mathrm{C} 10$ & 90 & 10 & 90.83 & 9.17 & 5.815 & 7.152 & 81.30 \\
\hline $\mathrm{C} 15$ & 85 & 15 & 86.18 & 13.82 & 5.957 & 7.186 & 82.90 \\
\hline $\mathrm{C} 20$ & 80 & 20 & 81.49 & 18.51 & 6.041 & 7.219 & 83.68 \\
\hline
\end{tabular}

${ }^{*}$ Density of $\mathrm{AP}=7.087 \mathrm{~g} / \mathrm{cm}^{3}$, Density of $\mathrm{CIP}=7.8 \mathrm{~g} / \mathrm{cm}^{3}$

We next analyzed the magnetic properties of AP and hybrid SMCs. Figure 3 shows the effective permeability $\left(\mu_{\mathrm{e}}\right)$, core loss per unit volume $\left(P_{c v}\right)$, and DC-bias characteristics of the C0-C20 samples. As can be seen in Figure $3 \mathrm{a}$, the $\mu_{\mathrm{e}}$ of all samples was preserved constantly up to the frequency of $1 \mathrm{MHz}$. Obviously, $\mu_{\mathrm{e}}$ tends to increase as CIP mass ratio increases. $\mathrm{C} 0$ shows the lowest $\mu_{\mathrm{e}}$ of 34.63 at $1 \mathrm{MHz}$, and C20 shows the highest $\mu_{\mathrm{e}}$ of 56.45 at $1 \mathrm{MHz}$. It is obvious that the addition of CIP particles to the core effectively enhanced the core permeability; this is attributed to the highly compacted core in which CIP particles magnetically bridge AP particles and AP particles rotate their magnetic domain much more efficiently than do the pure AP cores.
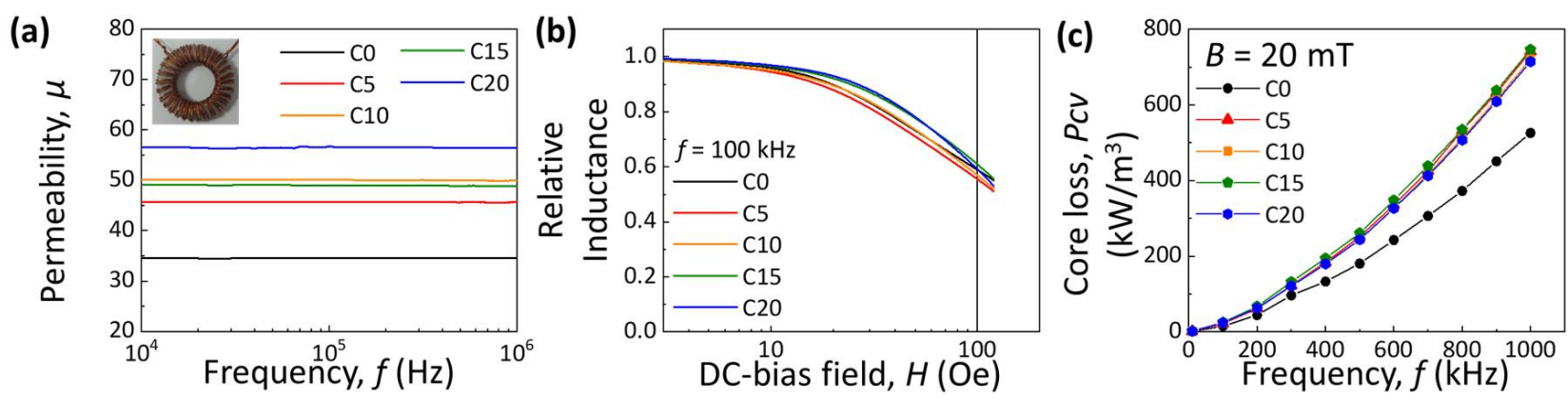

Figure 3. (a) Frequency dependence of permeability of amorphous SMCs with 0-20 wt.\% CIPs. Inset shows wire-wound core sample. (b) Relative inductance (\%) with applied DC-bias field for amorphous SMCs with 0-20 wt.\% carbonyl-iron. (c) Core loss of amorphous SMCs with 0-20 wt.\% carbonyl-iron as a function of frequency at $B_{m}=20 \mathrm{mT}$.

It is well known that, compared to the intrinsic permeability of the materials, spherical particles show severely deteriorated permeability due to the maximized demagnetizing field inside the powder. For SMCs comprising powder and inevitable inter-spacing between particles, the permeability of SMC decreased due to the incorporation of pores in the core; this decrease can be calculated using the following Ollendorf's equation [27],

$$
\mu=\frac{\eta \mu_{0}\left(\mu_{m}-\mu_{0}\right)}{N(1-\eta)\left(\mu_{m}-\mu_{0}\right)+\mu_{0}}
$$


where $\mu, \mu_{0}, \mu_{m}, \eta$, and $N$ are the relative permeability of the magnetic powder cores, the vacuum permeability, the intrinsic permeability of material, the volume packing fraction, and the coefficient of demagnetizing field $(0 \leq N \leq 1)$, respectively. By the addition of a small amount (5 20 wt.\%) of CIP particles in the AP SMC, $\eta$ increases, leading to a significant increase in permeability. With the addition of $20 \mathrm{wt} . \%$ CIP in SMC, a remarkable $63 \%$ increase in $\mu_{\mathrm{e}}$ was observed. It is obvious that mixing AP with small-sized CIP particles to make multimodal cores is an effective way of enhancing the permeability of SMC.

The DC bias characteristics of AP and hybrid SMCs were also evaluated. The DCbias dependence of the relative inductance at $100 \mathrm{kHz}$ of the cores with different CIP mass fractions is shown in Figure 3b; the C0-C20 cores show inductance retention levels of $55-61 \%$ at DC bias field of 100 Oe. The DC-bias characteristics tend to decreases as the core density and permeability increases, in this case, that the materials more rapidly reach saturated magnetization. The addition of CIP particles in the core increases the core density; however, the DC bias characteristics were preserved above $55 \%$. For the C20 core, even though the permeability increased $63 \%$ compared with that of C0 core, DC bias characteristics of $61 \%$ were observed. The high DC bias characteristics of hybrid cores are attributed to the high $M_{\mathrm{S}}$ of CIP particles. Consequently, by adding a small amount of CIP to the core, it is possible to increase the permeability without losing the DC bias characteristics.

Figure $3 c$ shows the core loss of C0-C20 samples measured at $f=10-1000 \mathrm{kHz}$ with $B_{m}=20 \mathrm{mT}$. The AP core showed the lowest core loss; the hybrid core with CIP showed relatively high core loss. The amorphous core mixed with CIP showed similar core loss values regardless of the weight fraction of CIP. In general, $P_{c v}$ is composed of hysteresis loss $\left(P_{h v}\right)$, eddy current loss $\left(P_{e v}\right)$, and abnormal loss $\left(P_{a v}\right)$ (or residual loss $\left.\left(P_{r v}\right)\right)$ per unit volume. The frequency dependence of $P_{a v}$ is generally complicated, however in SMCs, it was found to be proportional to the square of the frequency. Therefore, the core loss of SMCs for frequencies below $1 \mathrm{MHz}$ can be expressed simply by the following Equation (4) [28,29].

$$
P_{c v}=P_{h v}+P_{e v}+P_{a v}=K_{h} f+K_{d y n} f^{2}
$$

where $f$ is the frequency, and $K_{h}$ and $K_{d y n}$ represent the hysteresis loss and the dynamic loss coefficients, respectively. The $K_{d y n}$ comprises both the eddy current and anomalous loss coefficients $\left(K_{d y n}=K_{e}+K_{a}\right)$.

By the fitting frequency-core loss curve with Equation (4), we can separate $P_{c v}$ into $P_{h v}$ and $P_{e v}+P_{a v} . P_{h v}$ dominates at the low frequency of $100 \mathrm{kHz}$; however, as the frequency increases, the portion of $P_{e v}+P_{a v}$ dramatically increases, and $P_{e v}+P_{a v}$ dominates at $1 \mathrm{MHz}$.

Eddy current loss for spherical powder can be expressed by the following Equation (5) [30].

$$
P_{e}=\frac{(\pi B D f)^{2}}{20 \rho}
$$

where $P_{e}$ is the eddy current loss, $B$ is the excited maximum magnetic flux density, $D$ is the particle size, and $\rho$ is the resistivity of the particles.

Eddy current loss dominates in the high-frequency region; it is proportional to the square of the frequency. The measured coercive field of AP core and multimodal core $(\mathrm{AP}+\mathrm{CIP})$ is shown in Table 2. Obviously, the addition of CIP in the AP core significantly increases the coercive field of the core. When CIP is added to the core, the hysteresis loss is increased due to the higher coercive field of CIP compared with that of APs [31]. In addition, amorphous material has higher electrical resistivity than crystalline material [32]. As can be seen from Equation (5), as the resistivity increases, the eddy current loss decreases. However, in this study, the content of AP with high resistivity was decreased and the content of CIP with low resistivity was increased to improve permeability. Therefore, the eddy current loss may increase due to the addition of CIP with low resistivity. Consequently, the increased core loss of multimodal core $(\mathrm{AP}+\mathrm{CIP})$ is attributed to both increased hysteresis loss and dynamic loss (eddy current loss + abnormal loss). 
Table 2. The coercive field $\left(H_{c}\right)$ and derived hysteresis loss constant $\left(K_{h}\right)$ and dynamic loss constant $\left(K_{d y n}=K_{e}+K_{a}\right)$ of amorphous SMCs with 0-20 wt.\% CIPs.

\begin{tabular}{cccc}
\hline Sample & $\boldsymbol{H}_{\boldsymbol{c}}(\mathbf{k A} / \mathbf{m})$ & $\boldsymbol{K}_{\boldsymbol{h}}$ & $\boldsymbol{K}_{d y \boldsymbol{n}}\left(\boldsymbol{K}_{\boldsymbol{e}}+\boldsymbol{K}_{\boldsymbol{a}}\right)$ \\
\hline C0 & 0.00326 & 0.2035 & $3.27 \times 10^{-4}$ \\
$\mathrm{C} 5$ & 0.01497 & 0.2636 & $4.86 \times 10^{-4}$ \\
C10 & 0.01565 & 0.2628 & $4.65 \times 10^{-4}$ \\
C15 & 0.01706 & 0.3038 & $4.49 \times 10^{-4}$ \\
C20 & 0.02145 & 0.2664 & $4.54 \times 10^{-4}$ \\
\hline
\end{tabular}

Eddy current loss can be attributed to inter-particle eddy currents and intra-particle eddy current. Intra-particle eddy currents are highly dependent on the resistivity of the powders and are hard to manipulate during the core fabrication process; on the other hand, inter-particle eddy currents can be effectively minimized by surface insulation coating on the powders. It is doubtful that the incorporation of CIP at the voids between AP particles will increase the electrical connection between powders and increase inter-particle eddy current loss. However, it is still unclear whether the origin of $P_{e}$ is inter-particle eddy current or intra-particle eddy currents. To confirm whether the eddy current loss of the hybrid core is dominated by inter- or intra-particles eddy currents, or as to reduce inter-particle eddy current loss, we put insulation coating on AP and CIP, and examined the effect of insulation coating on the magnetic properties of SMCs.

For the insulation, $\mathrm{AP}$ and CIP were coated with $\mathrm{SiO}_{2}$ layers through the solutionbased sol-gel process. Figure 4 shows the analysis results for the insulated AP and insulated CIP. Figure 4a shows the XRD results of insulated AP and insulated CIP. AP shows a confirmed halo pattern with approximately $2 \theta=45^{\circ}$; CIP shows a confirmed $\alpha$-Fe peak (JCPDF\#87-0721). Due to the thin layer of coating and its amorphous nature, no peak of the insulating material $\mathrm{SiO}_{2}$ was found. Figure $4 \mathrm{~b}$ shows VSM measurement results for insulated AP and insulated CIP. The saturation magnetization of the insulated AP is $128 \mathrm{emu} / \mathrm{g}$, lower than that before coating; the saturation magnetization of the insulated $\mathrm{CIP}$ is $208 \mathrm{emu} / \mathrm{g}$, similar to that before coating. The slight decrease in $M_{\mathrm{S}}$ is attributed to the non-magnetic surface $\mathrm{SiO}_{2}$ layer.

Figure $4 \mathrm{c}, \mathrm{d}$ show surface SEM images of the insulated AP and insulated CIP. The AP surface becomes rough compared with that of pristine $\mathrm{AP}$, and aggregates of $\mathrm{SiO}_{2}$ were observed on the surface. As can be seen in the EDS mapping results in Figure 4e,f, Fe and Si peaks were present for both insulated AP and insulated CIP in the regions where the powder particles were located, and O peaks were located in the region around the powder particles; these observations show that $\mathrm{AP}$ and $\mathrm{CIP}$ were successfully coated with $\mathrm{SiO}_{2}$.

For the preparation of SMCs, five different types of cores were prepared: AP, AP with $\mathrm{CIP}, \mathrm{AP} @ \mathrm{SiO}_{2}$ with $\mathrm{CIP}$, AP with $\mathrm{CIP@SiO}{ }_{2}$, and $\mathrm{AP} @ S i \mathrm{O}_{2}$ with $\mathrm{CIP@SiO}{ }_{2}$. SEM images of polished surfaces of the above five types of cores are provided in Figure 2a,e, Figure 5a,c Fractures or degradation of the insulation layer during compaction were not observed. EDS line scans across the contact interface between particles, shown in Figure 5d, also support the preservation of the $\mathrm{SiO}_{2}$ insulation layer on the powder surface. 

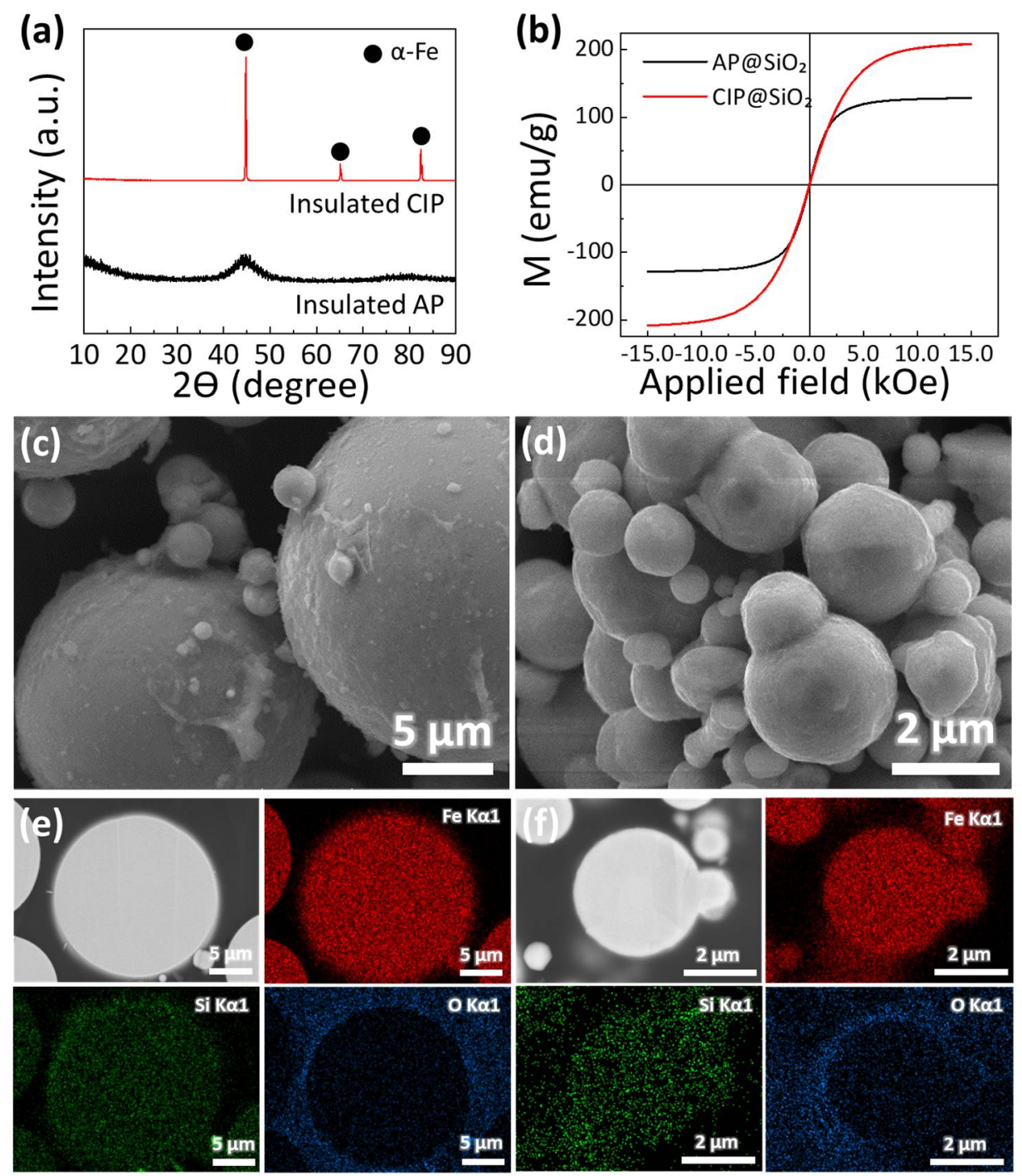

Figure 4. (a) XRD pattern of insulated amorphous powder and insulated carbonyl-iron powder. (b) Magnetic hysteresis loops of insulated amorphous powder and insulated carbonyl-iron powder. (c,d) SEM surface images of insulated (c) amorphous powder and (d) carbonyl-iron powder. (e,f) EDS element mapping results of insulated (e) amorphous powder and (f) CIPs.

Figure 6 shows the magnetic properties (permeability, core loss, and DC-bias properties) of the five different types of SMCs. As can be seen in Figure 6a, the permeability of all samples was kept constant up to $1 \mathrm{MHz}$. In particular, compared to the AP + CIP core, the $\mathrm{AP} @ \mathrm{SiO}_{2}+\mathrm{CIP}, \mathrm{AP}+\mathrm{CIP} @ \mathrm{SiO}_{2}$, and AP@SiO $2+\mathrm{CIP} @ \mathrm{SiO}_{2}$ cores showed significantly decreased permeability. This is understandable if we consider the decreased core density and inclusion of non-magnetic inter-particle insulations layers. Non-magnetic insulation layers with low density were included in the core due to $\mathrm{SiO}_{2}$ coating, resulting in a decrease in core density. The core density of each core is shown in Table 3. As shown in Equation (3), when the non-magnetic material increases, the volume packing fraction of the magnetic material decreases, so that the magnetic permeability decreases. 

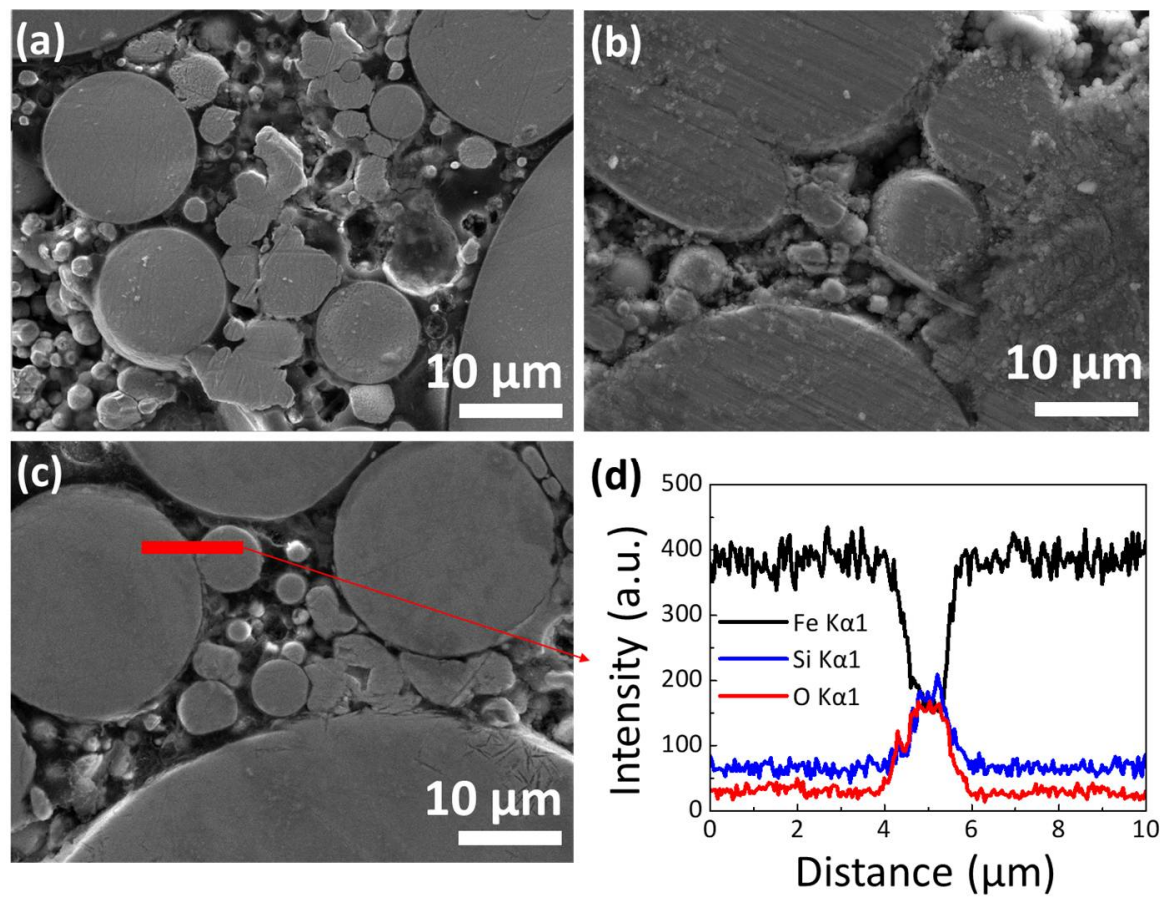

Figure 5. $(\mathbf{a}-\mathbf{c})$ Cross-section SEM images of (a) insulated amorphous SMCs with 20 wt.\% CIPs, (b) amorphous SMCs with $20 \mathrm{wt} . \%$ insulated carbonyl-iron, and (c) insulated amorphous SMCs with 20 wt.\% insulated CIPs. (d) EDS line scan analysis of insulated amorphous SMCs with 20 wt.\% insulated CIPs.

(a)

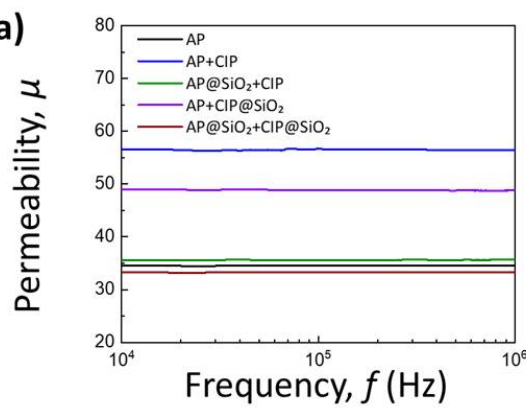

(b)

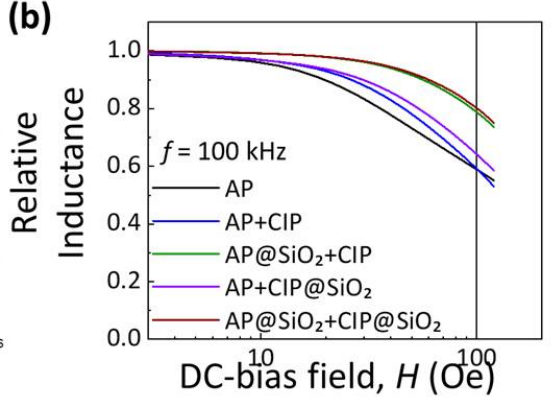

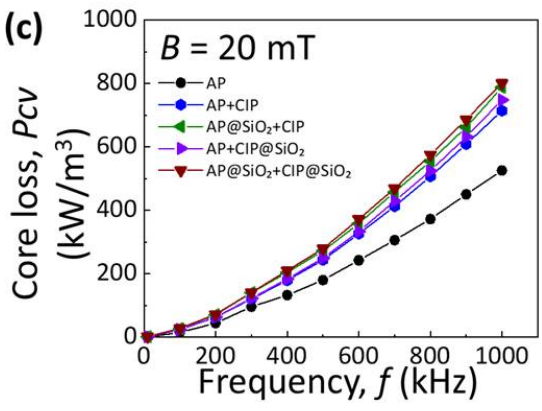

Figure 6. (a) Frequency-dependent permeability of insulated SMCs. (b) Relative inductance (\%) with applied DC-bias field for insulated SMCs. (c) Core loss of insulated SMCs as function of frequency at $B_{m}=20 \mathrm{mT}$.

Besides this, the effect of powder surface insulation on the DC-bias characteristics of the cores was opposite to that on the permeability. The DC-bias performance at $100 \mathrm{kHz}$ of five different types of cores is shown in Figure $6 \mathrm{~b}$. In the case of the core using insulated AP powder, DC-bias superimposing retention level increased, while permeability decreased. In particular, the hybrid core comprising $\mathrm{AP} @ \mathrm{SiO}_{2}+\mathrm{CIP}_{\mathrm{S}} \mathrm{SiO}_{2}$ showed DC-bias properties of more than $79 \%$ at $H=100$ Oe, with permeability similar to that of the AP core. DCbias characteristics of insulated hybrid cores are also attributable to the inclusion of nonmagnetic inter-particle insulation layers, which decrease the permeability of the cores, leading to a higher required level of applied magnetic field for the magnetic saturation. Through the controlled incorporation of CIPs and insulation coating of the powders, it is possible to modulate the electromagnetic properties, including the permeability and DC-bias characteristics of the hybrid cores. 
Table 3. Comparison of density and electromagnetic properties between hybrid SMCs.

\begin{tabular}{|c|c|c|c|c|c|}
\hline \multirow{2}{*}{ Sample } & \multirow{2}{*}{$\begin{array}{l}\text { Density } \\
\left(\mathrm{g} / \mathrm{cm}^{3}\right)\end{array}$} & \multirow{2}{*}{$\begin{array}{l}\text { Permeability } \\
\qquad f=1 \mathrm{MHz}\end{array}$} & \multicolumn{2}{|c|}{ Core Loss, $P_{c v}\left(\mathrm{~kW} / \mathrm{m}^{3}\right)$} & \multirow{2}{*}{$\begin{array}{c}\text { DC-Bias (\%) } \\
100 \mathrm{Oe}\end{array}$} \\
\hline & & & $100 \mathrm{kHz} / 50 \mathrm{mT}$ & $100 \mathrm{kHz} / 100 \mathrm{mT}$ & \\
\hline $\mathrm{AP}(=\mathrm{C} 0)$ & 5.429 & 34.63 & 159.29 & 571.19 & 59.12 \\
\hline $\mathrm{AP}+\mathrm{CIP}(=\mathrm{C} 20)$ & 6.041 & 56.45 & 201.03 & 1004.1 & 59.46 \\
\hline $\mathrm{AP} @ \mathrm{SiO}_{2}+\mathrm{CIP}$ & 5.837 & 35.70 & 263.96 & 1195.2 & 79.06 \\
\hline $\mathrm{AP}+\mathrm{CIP} @ \mathrm{SiO}_{2}$ & 5.953 & 48.81 & 231.50 & 1041.7 & 64.50 \\
\hline $\mathrm{AP} @ \mathrm{SiO}_{2}+\mathrm{CIP} @ \mathrm{SiO}_{2}$ & 5.769 & 33.34 & 257.66 & 1202.4 & 80.43 \\
\hline
\end{tabular}

Figure 6c shows the frequency-dependent core loss of the six different SMCs. The AP core without insulating layer showed the lowest core loss, while the $\mathrm{AP} @ \mathrm{SiO}_{2}+\mathrm{CIP@SiO}$ core showed the highest core loss. It is expected that the eddy current loss, especially at high frequency, will decrease due to the improved electrical insulation between powders. However, there were only negligible differences among loss values of the AP + CIP, $\mathrm{AP} @ \mathrm{SiO}_{2}+\mathrm{CIP}, \mathrm{AP}+\mathrm{CIP@SiO}$, and $\mathrm{AP} @ \mathrm{SiO}_{2}+\mathrm{CIP@SiO}{ }_{2}$ cores. Surface insulation of $\mathrm{AP}$ or CIP did not reduce core loss; rather, it slightly increased core loss. Such behavior was preserved at $1 \mathrm{MHz}$. Consequently, the $P_{e}$ of the hybrid core was found to dominantly originate from intra-particle eddy currents; and inter-particle eddy currents were negligibly small. This means that epoxy coating on powders was sufficient to block inter-particle eddy currents. In the core loss separation results shown in Table $4, P_{\mathrm{h}}$ and $P_{\mathrm{e}}$ are almost identical for the four different cores of AP + CIP, $\mathrm{AP} @ \mathrm{SiO}_{2}+\mathrm{CIP}, \mathrm{AP}+\mathrm{CIP} @ \mathrm{SiO}_{2}$, and $\mathrm{AP} @ \mathrm{SiO}_{2}+\mathrm{CIP} @ \mathrm{SiO}_{2}$, even at a frequency of $1 \mathrm{MHz}$.

Table 4. Derived hysteresis loss constant $\left(K_{h}\right)$ and dynamic loss constant $\left(K_{d y n}=K_{e}+K_{a}\right)$ of insulated SMCs.

\begin{tabular}{ccc}
\hline Sample & $\boldsymbol{K}_{\boldsymbol{h}}$ & $\boldsymbol{K}_{\boldsymbol{d y n}}\left(\boldsymbol{K}_{\boldsymbol{e}}+\boldsymbol{K}_{\boldsymbol{a}}\right)$ \\
\hline $\mathrm{AP}(=\mathrm{C} 0)$ & 0.2035 & $3.27 \times 10^{-4}$ \\
$\mathrm{AP}+\mathrm{CIP}(=\mathrm{C} 20)$ & 0.2664 & $4.54 \times 10^{-4}$ \\
$\mathrm{AP} @ \mathrm{SiO}_{2}+\mathrm{CIP}$ & 0.3108 & $3.78 \times 10^{-4}$ \\
$\mathrm{AP}+\mathrm{CIP} @ \mathrm{SiO}_{2}$ & 0.2587 & $4.94 \times 10^{-4}$ \\
$\mathrm{AP@SiO}+\mathrm{CIP@SiO}$ & $4.84 \times 10^{-4}$ \\
\hline
\end{tabular}

\section{Conclusions}

In summary, gas-atomized $\mathrm{Fe}_{73} \mathrm{Si}_{6} \mathrm{~B}_{10} \mathrm{P}_{5} \mathrm{C}_{3} \mathrm{Mo}_{3}$ amorphous powder cores mixed with carbonyl-iron powder were successfully manufactured, and the systematic investigation of their electromagnetic properties is presented. In addition, $\mathrm{SiO}_{2}$ insulation coating on powders was performed through a simple sol-gel process; its effect on the magnetic properties of the hybrid core was investigated. The following conclusions can be drawn from this work.

- CIPs are selectively incorporated in voids between APs; they deform during compaction and effectively reduce pores, resulting in the high packing density of cores.

- CIPs magnetically bridge APs and APs rotate their magnetic domains more efficiently than the pure AP cores, resulting in significantly increased permeability of cores. The addition of $20 \mathrm{wt} . \%$ CIP in SMC showed constant effective permeability from 57 up to $1 \mathrm{MHz}$, a remarkable $63 \%$ increase compared with the AP core.

- With the help of the high saturation magnetization of CIPs, DC bias superimposing retention level of $61 \%$ was secured for the CIP-added hybrid core.

Surface $\mathrm{SiO}_{2}$ insulation layers prepared by the sol-gel process were preserved after the high-pressure compaction process, and electrical insulation between powders was secured. It is revealed that the high-frequency dynamic loss of the hybrid core originated from intra-particle eddy current loss and anomalous loss component; inter-particle eddy currents are negligibly small. 
We believe that our approach to AP/CIP multimodal hybrid SMCs is an effective way of achieving high permeability as well as DC bias characteristics at high frequencies, and will be highly beneficial for the miniaturization of power inductors.

Author Contributions: Conceptualization, J.-W.J.; methodology, H.-R.K.; validation, S.-S.Y.; formal analysis, M.-S.J.; investigation, Y.-G.N.; writing—original draft preparation, H.-R.K.; writing—review and editing, J.-W.J. and Y.-S.K.; supervision and project administration, J.-W.J.; funding acquisition, Y.-J.K. All authors have read and agreed to the published version of the manuscript.

Funding: This research was funded by Defense Acquisition Program Administration, Grant number (18-CM-MA-15), and by Korea Institute of Materials Science (KIMS), Grant number PNK7640.

Data Availability Statement: Data presented in this article are available at request from the corresponding author.

Conflicts of Interest: The authors declare no conflict of interest.

\section{References}

1. Hasegawa, R. Present status of amorphous soft magnetic alloys. J. Magn. Magn. Mater. 2000, 215-216, 240-245. [CrossRef]

2. Yoshida, S.; Mizushima, T.; Hatanai, T.; Inoue, A. Preparation of new amorphous powder cores using Fe-based glassy alloy. IEEE Trans. Magn. 2000, 36, 3424-3429. [CrossRef]

3. Hasegawa, R.; Hathaway, R.E.; Chang, C.F. Magnetic properties of consolidated glassy metal powder cores. J. Appl. Phys. 1985, 57, 3566-3568. [CrossRef]

4. Inoue, A. Stabilization of metallic supercooled liquid and bulk amorphous alloys. Acta Mater. 2000, 48, 279-306. [CrossRef]

5. Masumoto, T.; Suzuki, K.; Fujimori, H.; Hashimoto, K. Materials Science of Amorphous Metals; Ohm Publication: Tokyo, Japan, 1982; pp. 7-20.

6. Kikuchi, M.; Fujimori, H.; Obi, Y.; Masumoto, T. New Amorphous Ferromagnets with Low Coercive Force. Jpn. J. Appl. Phys. 1975, 14, 1077-1078. [CrossRef]

7. Kohmoto, O.; Fujishima, H.; Ojima, T. Magnetic annealing of zero magnetostrictive amorphous alloy with high saturation induction. IEEE Trans. Magn. 1980, 16, 440-443. [CrossRef]

8. Liu, Y.; Niu, S.; Li, F.; Zhu, Y.; He, Y. Preparation of amorphous Fe-based magnetic powder by water atomization. Powder Technol. 2011, 213, 36-40. [CrossRef]

9. Kim, Y.B.; Jang, D.H.; Seok, H.K.; Kim, K.Y. Fabrication of Fe-Si-B based amorphous powder cores by cold pressing and their magnetic properties. Mater. Sci. Eng. A 2007, 449-451, 389-393. [CrossRef]

10. Neamţu, B.V.; Marinca, T.F.; Chicinaş, I.; Isnard, O.; Popa, F.; Păşcuţă, P. Preparation and soft magnetic properties of spark plasma sintered compacts based on Fe-Si-B glassy powder. J. Alloys Compd. 2014, 600, 1-7. [CrossRef]

11. Chen, H.S. Glassy metals. Rep. Prog. Phys. 1980, 43, 353-432. [CrossRef]

12. Luborsky, F.E. Magnetic properties of amorphous alloys. J. Magn. Magn. Mater. 1978, 7, 143-149. [CrossRef]

13. Wun-Fogle, M.; Restorff, J.B.; Cuseo, J.M.; Garshelis, I.J.; Bitar, S. Magnetostriction and magnetization of common high strength steels. IEEE Trans. Magn. 2009, 45, 4112-4115. [CrossRef]

14. Stearns, M.B. Internal Magnetic Fields, Isomer Shifts, and Relative Abundances of the Various Fe Sites in FeSi Alloys. Phys. Rev. 1963, 129, 1136-1144. [CrossRef]

15. Ciftci, N.; Ellendt, N.; Coulthard, G.; Barreto, E.S.; Mädler, L.; Uhlenwinkel, V. Novel cooling rate correlations in molten metal gas atomization. Metall. Mater. Trans. B 2019, 50, 666-677. [CrossRef]

16. Chang, L.; Zhang, Y.; Dong, Y.; Li, Q.; He, A.; Chang, C.; Wang, X. Enhanced magnetic properties of Fe-based nanocrystalline composites by addition of carbonyl iron powders. SN Appl. Sci. 2019, 1, 1-7. [CrossRef]

17. Kim, H.-J.; Nam, S.K.; Kim, K.-S.; Yoon, S.C.; Sohn, K.-Y.; Kim, M.-R.; Song, Y.S.; Park, W.-W. Magnetic properties of amorphous Fe-Si-B powder cores mixed with pure iron powder. Jpn. J. Appl. Phys. 2012, 51, 103001. [CrossRef]

18. Chang, C.; Guo, J.; Li, Q.; Zhou, S.; Liu, M.; Dong, Y. Improvement of soft magnetic properties of FeSiBPNb amorphous powder cores by addition of FeSi powder. J. Alloys Compd. 2019, 788, 1177-1181. [CrossRef]

19. Xia, C.; Peng, Y.; Yi, X.; Yao, Z.; Zhu, Y.; Hu, G. Improved magnetic properties of FeSiCr amorphous soft magnetic composites by adding carbonyl iron powder. J. Non-Cryst. Solids 2021, 559, 120673. [CrossRef]

20. German, R.M. Powder Metallurgy and Particulate Materials Processing: The Processes, Materials, Products, Properties and Applications; Metal Powder Industries Federation Princeton: Princeton, NJ, USA, 2005; pp. 130-132.

21. Japka, J.E. Microstructure and properties of carbonyl iron powder. JOM 1988, 40, 18-21. [CrossRef]

22. Zhou, B.; Dong, Y.; Liu, L.; Chang, L.; Bi, F.; Wang, X. Enhanced soft magnetic properties of the Fe-based amorphous powder cores with novel $\mathrm{TiO}_{2}$ insulation coating layer. J. Magn. Magn. Mater. 2019, 474, 1-8. [CrossRef]

23. Wang, C.; Guo, Z.; Wang, J.; Sun, H.; Chen, D.; Chen, W.; Liu, X. Industry-oriented Fe-based amorphous soft magnetic composites with $\mathrm{SiO}_{2}$-coated layer by one-pot high-efficient synthesis method. J. Magn. Magn. Mater. 2020, 509, 166924. [CrossRef] 
24. Xiaolong, L.; Yaqiang, D.; Min, L.; Chuntao, C.; Xin-Min, W. New Fe-based amorphous soft magnetic composites with significant enhancement of magnetic properties by compositing with nano-(NiZn) $\mathrm{Fe}_{2} \mathrm{O}_{4}$. J. Alloys Compd. 2017, 696, 1323-1328. [CrossRef]

25. Chen, Z.; Liu, X.; Kan, X.; Wang, Z.; Zhu, R.; Yang, W.; Wu, Q.; Shezad, M. Phosphate coatings evolution study and effects of ultrasonic on soft magnetic properties of FeSiAl by aqueous phosphoric acid solution passivation. J. Alloys Compd. 2019, 783, 434-440. [CrossRef]

26. Matos, M.C.; Ilharco, L.M.; Almeida, R.M. The evolution of TEOS to silica gel and glass by vibrational spectroscopy. J. Non.Cryst. Solids 1992, 147-148, 232-237. [CrossRef]

27. Ollendorff, F. Magnetostatik der massekerne. Arch. Elektrotech. 1931, 25, 436-447. [CrossRef]

28. Xie, D.-Z.; Lin, K.-H.; Lin, S.-T. Effects of processed parameters on the magnetic performance of a powder magnetic core. J. Magn. Magn. Mater. 2014, 353, 34-40. [CrossRef]

29. Yang, B.; Li, X.; Guo, R.; Yu, R. Oxidation fabrication and enhanced soft magnetic properties for core-shell $\mathrm{FeCo}_{\mathrm{C}} \mathrm{CoFe} \mathrm{O}_{4}$ micron-nano composites. Mater. Des. 2017, 121, 272-279. [CrossRef]

30. Takemoto, S.; Saito, T. Effects of crystal grain size and particle size on core loss for Fe-Si compressed cores. Mater. Sci. Forum 2007, 534, 1313-1316. [CrossRef]

31. Shokrollahi, H.; Janghorban, K. Soft magnetic composite materials (SMCs). J. Mater. Process. Technol. 2007, 189, 1-12. [CrossRef]

32. Guo, P.; Sarangan, A.M.; Agha, I. A review of germanium-antimony-telluride phase change materials for non-volatile memories and optical modulators. Appl. Sci. 2019, 9, 530. [CrossRef] 